\title{
EVALUATION OF VIRTUAL SAFETY TRAINING TOOL APPLICATION WITH CONSTRUCTION WORKERS
}

\author{
Zaki Marwa, and Semra Çomu Yapıcı \\ Bogazici University, Istanbul, Turkey
}

\begin{abstract}
Construction sites can be categorized as one of the most high-risk workplaces in terms of occupational safety. Previous studies indicate that highly engaging safety training tools mitigate on-site accidents. In this regard, virtual technologies are encouraged to be used in the development of the safety training tools in the construction industry since they provide visualization, multiuser interactions and task compatibility. In this study, we utilized a virtual safety training tool entitled V-SAFE.v2 which includes only scaffolding task sequence and framework installation processes. VSAFE.v2 is a highly engaging safety training tool which enable workers to collaborate with each other and gain safety knowledge in an interactive way. In this study, the applicability and efficiency of this training tool were examined at a real construction site. The experiments were conducted with seven construction workers. The effectiveness of $\mathrm{V}$ SAFE.v2 training on their safety knowledge was examined by a comparative analysis. According to the results, V-SAFE.v2 has a potential to increase awareness of the construction workers on the occupational safety issues.
\end{abstract}

\section{Introduction}

The construction industry is considered as one of the most dangerous industries due to its temporary and dynamic nature (Al-Humaidi and Tan, 2010; Fang and $\mathrm{Wu}, 2013)$. Statistics have shown that the number of accidents occurs in the construction industry is higher than any other industry (Eurostat). Mohammadi et al (2018) mentioned that even though the workers in the construction industry account for only $6 \%$ of total workers in other industries, the percentage of construction industry fatalities is $20 \%$. Although, the percentage of fatalities is considered to be very high, this figure cannot be held against the fact that the construction industry is growing rapidly. Therefore, in order for the construction companies to show growth and progress in the industry, health and safety management should be given special attention.

According to the occupational safety and health administration (OSHA) in the United States, there are about $65 \%$ of the construction industry workers work on scaffolds, and about $72 \%$ of the workers injured in scaffold accidents. Therefore, trying to protect these workers may prevent about 4500 injuries and about 60 deaths every year (Bureau of Labor Statistics (BLS). High fatal and non-fatal accident rates of the construction industry are also a serious problem in European Union countries. According to Eurostat 2016 database, a total of 3546 fatal accidents occurred in 28 European Union countries and around $21 \%$ of these accidents appear in the construction sector.

Rubio-Romero et al. (2013) mentioned that $40 \%$ of construction site accidents in Spain caused by falling from heights, and about $30 \%$ of these accidents are caused by the falls from temporary construction devices such as scaffolds. There are many studies regarding the safety level of scaffolding equipment since it is considered as the major cause of falls from height accidents in the industry (Rubio-Romero et al. 2013). Some studies show the risk involved when handling more loads on "suspended scaffolds" (Saurin and Guimarães, 2006) while another study ensures about the ergonomically unsuitable techniques when disassembling scaffolding (Cutlip et al., 2000). Another study conducted in Poland by Hola et al. (2017), includes a set of 177 on-site scaffolding accidents. The study shows that $43.5 \%$ of accidents resulting severe body injuries, while about $35.6 \%$ of accidents cause light body injuries (Hola et al., 2017).

Therefore, falls from height accidents should have a high level of attention and proper training techniques should be implemented in order to improve the safety level in the construction industry. In this regard, the virtual environment is becoming one of the leading tools in the safety management field. It provides the workers a safe and easy way of learning. For this reason, the advantage of using virtual environments in the construction industry has fair attention and it should be implemented properly to reduce the number of fatalities and accidents occurring in construction sites. The purpose of this study is to test a virtual safety training tool with real construction workers in order to present the effectiveness and suitability of virtual environments.

\section{Background}

In recent years, virtual technologies are frequently used in many research areas related to occupational 
safety, such as construction, aviation and medicine. Virtual environments enable users to experience real world components in a computer simulated environment (Lovreglio 2018). It is also widely accepted that 3D games encourage the participants for difficult and risky activity training and provide recalling knowledge for a long period of time (Chittaro and Buttussi 2015). For all these reasons, there are various virtual technology-based safety training tools that have been developed and used in the construction industry over the last decade.

For example, Sacks and his colleagues (2013) developed a tool to identify workplace risks in the virtual construction environment. They conducted a study with 66 participants to test the efficiency of the simulation tool. The subjects were divided into two groups; one of them received traditional safety training by using $2 \mathrm{D}$ materials and the others were trained by the 3D immersive virtual environment to recognize the construction site hazards. According to the results, the second group trained in the 3D environment performed better in terms of identifying the workplace hazards. Guo et. al. (2012) conducted another study on safety training using virtual reality. In this study, the authors introduced and tested a multi-user safety training tool for dismantling a tower crane. In this study, project managers and crane operators used the game-based training tool and answered a survey related to both traditional and VR-based innovative training methods. The findings of the survey show that the crane operations will be safer and more efficient with the support of game-based training tools compared to traditional methods. Another study (Albert et. al., 2014) focused on the virtual reality technology to improve the hazard recognition skills of construction workers. The researchers developed a high fidelity augmented virtual environment and tested its feasibility with 6 workers. After defining the initial knowledge level of all participants by conducting a paper-based test, they walked in the virtual environment to identify the workplace hazards. Then, the same written test was applied to the participants again. The empirical test results indicated the participants increased their performance by $27 \%$ after experiencing the virtual environment.

Guo et al., (2016) compared the effectiveness of onsite training and off-site training. They concluded that on-site training is inactive and may have clashes with other construction activities, consequently, overall construction productivity can be reduced by the application of on-site safety training. On the other side, off-site safety training is poor in terms of hands-onpractice opportunity for construction workers. Virtual environment applications can ameliorate off-site hands-on-practice by mimicking real construction site therefore it can provide visualized information to trainees. Bhide et al., (2015) emphasize that virtual environment-based training is a bridge that closes the gap between learning by practice and learning in traditional classrooms. The same study also underlines that tracking the position and orientation of character according to reality is one of the main features of the virtual environment.

Hallowell et al., (2016) confirms that virtual environment applications increased the ability of trainees to reconnoiter buildings and infrastructure prior to site implementation, thereby increasing the recognition of hazards through design. Researchers approve that initial training is one of the most important aspects of competence on a construction site (Cameron et al., 2011; Hatala et al., 2014). Training can be improved further by providing feedback which allows the modification or control of a process using its anticipated results or effects. Therefore, integrating feedback feature into virtual environment applications will increase the effectiveness of safety-training (Lawani et al., 2018).

Even though many studies emphasize the advantage of using virtual environments in safety training, a limited number of studies clarify the role of virtual environments in scaffolding activities. Nadhim et al., (2016) mentioned that scaffolding activities are one of the major causes of falling-from-heights incidents. The study indicates that $23 \%$ of falling-from-height accidents occur during the assembling, disassembling or post-assembling activities of scaffolding. The same study points out that the second most serious cause of falling-from-height accidents depends on the learners' experience, lack of education or knowledge level. Moreover, Sawacha et al. (1998) show that scaffolding activities are one of the main causes of construction risks. Therefore, proper safety training is crucial in reducing the risks associated with scaffolding activities (Sawacha et al., 1998).

\section{Research Methodology}

In this study, our main objective is to train the site workers against construction hazards during scaffolding activities by using a virtual environmentbased safety training tool. For this purpose, we utilized the second version of V-SAFE.v2 which involves only scaffolding activities. V-SAFE.v2 provides a realistic working space to its users and ensures that they are exposed to potential construction accidents in a riskfree environment (Figure 1). Furthermore, V-SAFE.v2 is very user-friendly with its point-and-click design; particular attention was paid to the ease of use, as it was developed for construction workers. 


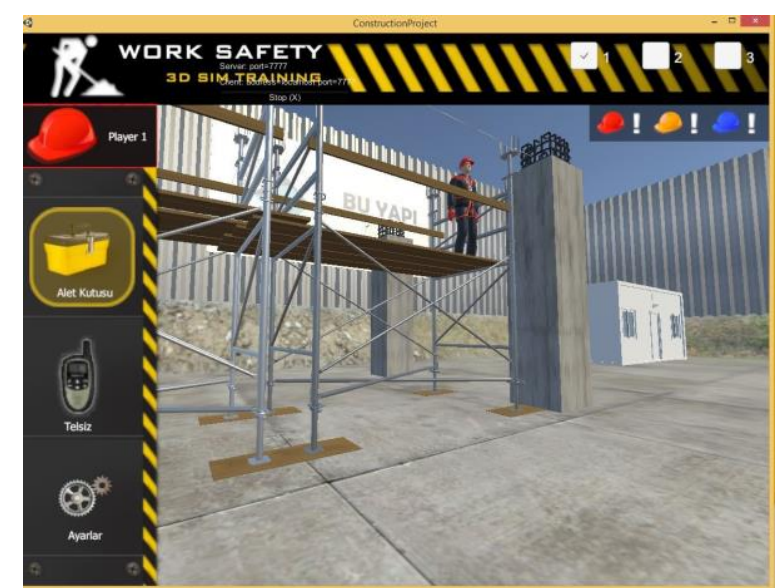

Figure 1: V-SAFE.v2

\section{V-SAFE.v2}

First of all, V-SAFE.v2 is supported by a cloud-based learning management system (Cloud LMS). By using Cloud LMS, the necessary information is stored and analyzed in the system. V-SAFE.v2 enables workers to be trained collaboratively through its multi-user feature. In real construction sites, workers communicate and interact with each other, therefore, in order for the tool to be efficient, workers should interact simultaneously during the training session.

There are three different modules in V-SAFE.v2; i) Training Module, ii) Test 1 Module, ii) Test 2 Module. In each module, up to three participants can be trained simultaneously. In the Training Module, V-SAFE.v2 guides the participants and provides necessary information through written assistance and flashing objects. In other words, workers learn how to safely perform the scaffolding activities. In Test 1 Module, participants perform the construction tasks without any guidance and the performance of each trainee is recorded automatically for providing feedbacks. The training tool can also be utilized by a single user, where the other two roles are controlled by an autonomous agent. The autonomous agents follow the right sequence of steps so that the software would be able to evaluate the individual worker performance.

Moreover, the Test 2 Module is also supported by autonomous agents which can perform the task incorrectly. Therefore, if the autonomous agent is selected in a way to act incorrectly, there will be an accident in Test 2 Module. Accordingly, all trainees could experience an accident that raises awareness of the consequences of catastrophic cases.

\section{Experiment Setting}

In this study, 7 construction workers participated in the experiments (Figure 2). The subjects were working in the roof installation team of a large-scale infrastructure project in Istanbul. The workers who built the roof assembly on the scaffold were experienced in the installation and dismantling of scaffolding.

The experiment is divided into 3 major steps. In the first step, workers were asked to fill a questionnaire that contains questions regarding their background, age, ability to use computers, experience on computer games, and their expertise in the construction industry. They also responded to a paper-based exam containing 10 multiple choice questions on scaffolding safety. Accordingly, the pre-training knowledge of workers on scaffolding safety is determined. In the second step, workers used the Training and Test 1 Modules of V-SAFE.v2, so the individual training performance of each worker is evaluated.

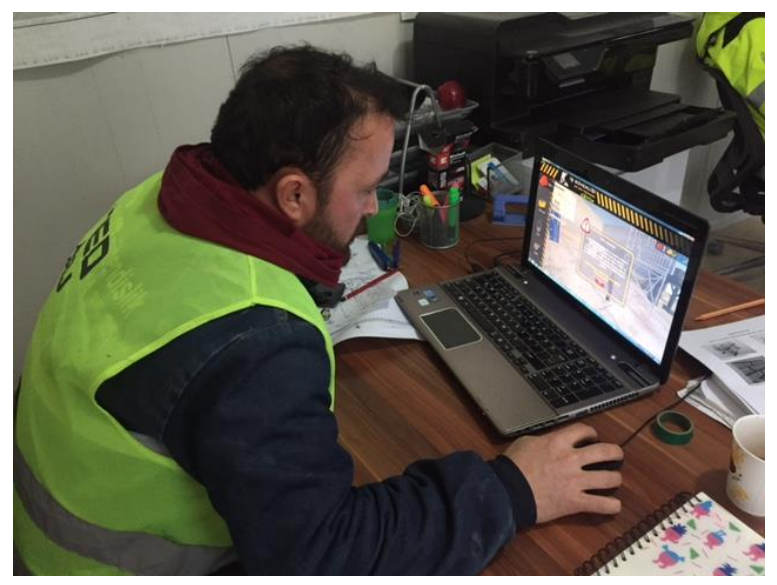

Figure 2: Experiment Participant

After completing the testing part, workers received a performance-based feedback report (Figure 3). Once they successfully finish the V-SAFE.v2 training, they were again asked to respond to the same exam questions. Hence, their pre-training and post-training answers are compared.

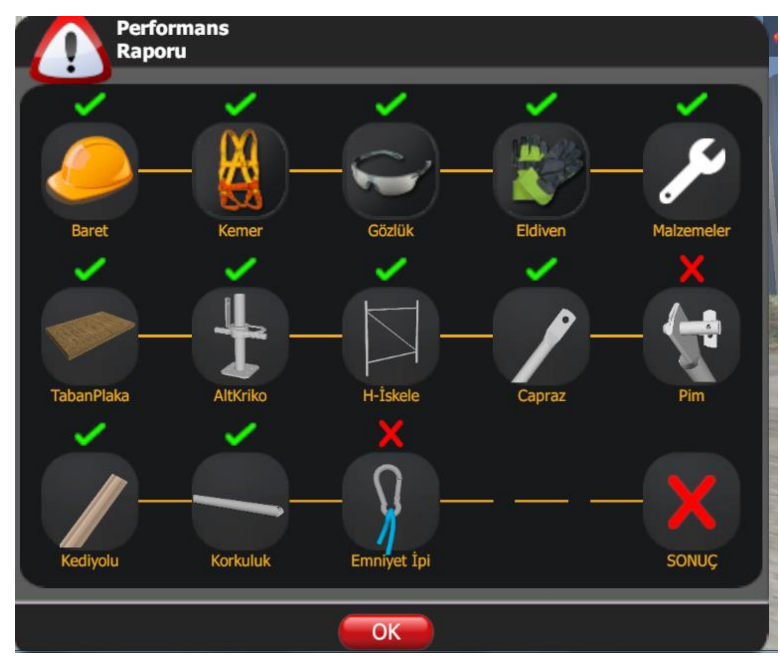

Figure 3: V-SAFE.v2 Feedback. 


\section{Results and Discussion}

A wide variety of construction activities incur site workers to hazards and scaffolding activities are one of the most dangerous construction activities. Therefore, ensuring safety on site is essential to keep workers away from hazard sources. In this respect, we aimed to develop an effective safety training method to simulate the scaffolding activities, which is an essential and common activity of almost all construction projects. For this purpose, we utilized the second version of V-SAFE, which involves only scaffolding activities.

In order to validate the effectiveness of V-SAFE.v2, we conducted an experiment with real construction workers who perform construction activities on scaffolds. Using construction workers in such experiments is not a common practice, a great percentage of scientific experiments were conducted using students or engineers who are well educated. Yet, most of the construction workers are uneducated, therefore it is extremely important directly using workers to collect their feedback on the tool rather than using engineers or students. Fang et al., (2015) mentioned that lack of education and training are the major reasons behind the worker's shortage of hazard recognition. Therefore, our research study is essential since we train workers and present their safety performance.

As shown in Table 1, 7 construction workers were selected to perform the experiment, they have different ages, site experience, and duties. As shown in the same table, only two of them have not played a computer game before, while the other five workers have played computer games. We also gathered information about the computer games they played. Only three of them have played 3D games, while the other 4 workers had never experienced a virtual environment before.

Table 1: Pre-test Questionnaire Results

\begin{tabular}{|l|c|c|c|l|l|}
\hline Participants & Age & Duty & $\begin{array}{c}\text { Experience } \\
\text { (years) }\end{array}$ & $\begin{array}{l}\text { Computer } \\
\text { Games }\end{array}$ & $\begin{array}{l}\text { 3D } \\
\text { Computer } \\
\text { Games }\end{array}$ \\
\hline CW1 & 31 & $\begin{array}{c}\text { Unskilled } \\
\text { Worker }\end{array}$ & 1 & Yes & No \\
\hline CW2 & 34 & Assembler & 12 & Yes & Yes \\
\hline CW3 & 49 & Assembler & 6 & No & No \\
\hline CW4 & 40 & Foreman & 20 & Yes & Yes \\
\hline CW5 & 27 & Assembler & 5 & Yes & Yes \\
\hline CW6 & 30 & Foreman & 10 & Yes & No \\
\hline CW7 & 39 & Assembler & 20 & No & No \\
\hline
\end{tabular}

In the first stage of the experiment, a paper based multiple choice exam was conducted to measure the occupational safety and scaffolding knowledge of the field workers before the training. We prepared the exam questions based on the scaffolding safety guideline published by The Ministry of Labor and Social Security in Turkey. In this test, the construction workers made an average of 5 mistakes in 10 questions. Following the written test, field workers received a highly engaging safety training on scaffolding activities through V-SAFE.v2. After completing the V-SAFE.v2 training phase, participants proceeded to the Test 1 Module, where they performed tasks without any guidance or assistance from the system. Participants who completed the V-SAFE.v2 test module responded to the same 10 questions. According to the written test results, participants made an average of 2.86 mistakes in 10 questions after receiving a highly engaging safety training through V-SAFE.v2. We then compared the pre-training and post-training exam scores using paired t test. According to the analysis results, a significant increase was observed in the test scores. In other words, participants performed better in the written exam after the training. This corresponds to the outcome of a study (Guo et al., 2016) that claims virtual reality safety training leads to better results than conventional way of training.

Table 2: Test Results (Pre-V-SAFE.v2 \& Post VSAFE.v2)

\begin{tabular}{|l|c|c|}
\hline \multirow{2}{*}{ Participant } & \multicolumn{2}{|c|}{$\begin{array}{c}\text { Paper-based Exam } \\
\text { \#of Mistakes }\end{array}$} \\
\cline { 2 - 3 } & Pre-V-Safe.v2 & Post-V-Safe.v2 \\
\hline CW1 & 5 & 3 \\
\hline CW2 & 5 & 3 \\
\hline CW3 & 5 & 3 \\
\hline CW4 & 5 & 2 \\
\hline CW5 & 5 & 3 \\
\hline CW6 & 5 & 4 \\
\hline CW7 & 5 & 2 \\
\hline Average & $\mathbf{5}$ & $\mathbf{2 . 8 6}$ \\
\hline
\end{tabular}

Cameron et al., (2011) discusses that training has a positive impact on trainees in terms of transforming theoretical information into reality. The experimental results also affirm that experiential learning is substantial in terms of scaffolding activities in $\mathrm{V}$ SAFE.v2. While participants could only answer half of the questions correctly, after training in a virtual environment, their safety knowledge is enhanced and the number of mistakes they made significantly reduced. Similarly, Hallowell et al. (2016) also showed that trainees are able to distinguish construction process sequences more clearly in the virtual environment. Therefore, one can conclude that enhanced spatial knowledge representation through 
virtual environment, enables greater opportunities for experiential learning.

\section{Conclusion}

To sum up, virtual technologies have been exceedingly used in the construction industry, however, a limited number of research has concentrated on using virtual environments for simulating scaffolding activities. These activities are common, complicated and expose workers to hazards, therefore, providing safety during scaffolding activities is essential. In the construction industry, virtual technology applications have been used in occupational safety in recent years. It is difficult for untrained construction workers without computer literacy to use complex safety tools based on virtual environments. However, V-SAFE.v2 is highly user-friendly, therefore the workers can perform the tasks without having any difficulty. The results show that the simplicity of application is required to achieve the desired results. The development of workers' safety knowledge is the most important indicator of the functionality of having a simple interface in the training tool. Many studies pointed out the importance of hands-on-practice during safety training, however, construction companies still prioritize the traditional safety training methods, such as presentations, and lectures, in which it fails to provide hands-on-practice. In this sense, V-SAFE.v2 provides a great opportunity of repetitive practice in a risk free environment. An important limitation of this study is about the number of participants, which is quite essential in such experiments, more than seven participants are required to truly conclude that the findings are significant. Furthermore, the study does not compare conventional ways of training with virtual training methods, future studies are planned to include the comparison of both methods. Furthermore, due to the small number of participants, the multiuser capabilities of V-SAFE.v2 were not utilized, however, the multiuser property has a high potential to increase the effectiveness of the tool in safety training. In a nutshell, in this study, we aim to train workers on scaffolding activities without any exposure to risk by using virtual environments. In this regard initial findings indicate that V-SAFE.v2 has a high potential in effective occupational safety training.

\section{Acknowledgments}

This material is based in part upon work supported by TUBITAK under Grant No. 315M186. Any opinions, findings, and conclusions or recommendations expressed in this material are those of the authors and do not necessarily reflect the views of TUBITAK.

\section{References}

Albert, A., Hallowell, M. R., Kleiner, B., Chen, A., and Golparvar-Fard, M. (2014). "Enhancing Construction Hazard Recognition with High-Fidelity Augmented Virtuality." Journal of Construction Engineering and Management.
Al-Humaidi, H.M., Tan, F.H., 2010. Construction safety in Kuwait. J. Perform. Constr. Facil 24 (1), 7077.

Bhide, S., Riad, R., Rabelo, L., Pastrana, J., Katsarsky, A., Ford, C., (2015) "Development of Virtual Reality Environment for Safety Training" Proceedings of the 2015 Industrial and Systems Engineering Research Conference.

Burke, M. J., Sarpy, S. A., Smith-Crowe, K., ChanSerafin, S., Salvador, R., and Islam, G. (2006) . Relative Effectiveness of Worker Safety and Health Training Methods. American Journal of Public Health, Vol 96, No. 2, 315-324.

Cameron, I., Hare, B., Duff, R., McNairney, F., 2011. Using Pictures in Training: The Impact of Pictorial OSH Training on Migrant Worker Behaviour and Competence. IOSH, Leicestershire, UK.

Chittaro, L., and Buttussi, F. (2015). Assessing knowledge retention of an immersive serious game vs. A traditional education method in aviation safety. IEEE Transactions on Visualization and Computer Graphics., 10.1109/TVCG.2015.2391853

Cutlip, R., Hsiao, H., Garcia, R., Becker, E., Mayeux, A., 2000. A comparison of different postures for scaffold end-frame disassembly. Applied Ergonomics 31 (2000), 507-513.

Dragone, D., Galeotti, F., Orsini, R., 2015 "Students, Temporary Workers and Co-Op Workers: An Experimental Investigation on Social Preferences" Games 2015, 6, 79-123; doi:10.3390/g6020079.

EuroStat https://ec.europa.eu/eurostat/statisticsexplained/index.php?title=Construction_statistics_A CE_Rev._2\&oldid=65060.

EuroStat https://ec.europa.eu/eurostat/statisticsexplained/index.php?title=Construction_statistics_A CE_Rev._2\&oldid=65060.

Fang, D., Wu, H., 2013. "Development of a Safety Culture Interaction (SCI) model for construction projects" Safety Science 57 (2013) 138-149.

Fang, Y., Cho,Y, K., 2015 “Analyzing Construction Workers' Recognition of Hazards by Estimating Visual Focus of Attention" The 6th International Conference on Construction Engineering and Project Management (ICCEPM 2015).

Guo, H., Li, H., Chan, G., and Skitmore, M. (2012). "Using game technologies to improve the safety of construction plant operations." Acc. Analy. and Prev.., 
Guo, H., Yu, Y., Skitmore, M., (2016) "Visualization technology-based construction safety management: A review" Automation in Construction 73 (2017) 135144.

Hallowell, M, R.,Hardison, D., Desvignes, M., 2016 "Information technology and safety integrating empirical safety risk data with building information modeling, sensing, and visualization technologies" Emerald Insight www.emeraldinsight.com/14714175.htm

Harasymiuk, J., Tadeusz Barski, J., 2017 “Accidents in Building Engineering in the European Union Countries in the Years 2008 - 2014" Conf. Ser.: Mater. Sci. Eng. 245082061.

Hasan, A., Jha, K.N., 2013. Safety incentive and penalty provisions in Indian construction projects and their impact on safety performance. Int.J.Injury ControlSaf.Promot.20 (1), 3-12.

Hatala, R., et al., 2014. Feedback for simulation-based procedural skills training: a metaanalysis and critical narrative synthesis. Adv. Health Sci. Educ. Theory Pract. 19 (2), 251-272.

Hoła. A., Hoła, B. and Szóstak M. 2017 “Analysis of the causes and consequences of falls from scaffolding using the Polish construction industry as an example" IOP Conf. Series: Materials Science and Engineering 251 (2017) 012050.

Jitwasinkul, B., Hadikusumo, B.H., 2011. Identification of important organisational factors influencing safety work behaviours in construction projects. J. Civ. Eng. Manage. 17 (4), 520-528.

Kassem, M., Benomran, L., Teizer, J., (2017), Virtual environments for safety learning in construction and engineering: seeking evidence and identifying gaps for future research.

Kiral, I.A., Çomu, S., Chen, J., Taylor, J.E. (2016). "Virtual Collaborative Safety Training for the Crane Operations", 16th International ConVR, Hong Kong, 11-13 Dec 2016.

Kolb, D.A. (1984) Experiential Learning: Experience as the Source of Learning and Development. Englewood Cliffs,N.J.: Prentice-Hall.

Lawani, K., Hare, B., Cameron, L., (2018) "Integrating early refresher practice in height safety and rescue training" Safety Science 110 (2018) 411417.
Lin, K., Son, J. W., \& Rojas, E. M. (2011). A pilot study of a 3D game environment for construction safety education. ITcon, 16, 69-84.

Lovreglio, R. (2018). A Review of Augmented Reality Applications for Building Evacuation. Augmented Reality for Technical Entrepreneurs 2016 Conference.

Mohammadi, A., Tavakolan, M., Khosravi, Y., 2018. "Factors influencing safety performance on construction projects: A review" Safety Science 109 (2018) 382-397.

Nadhim, E. A., Hon, C., Xia, B., Stewart, I., \& Fang, D. (2016). Falls from height in the construction industry: a critical review of the scientific literature. International journal of environmental research and public health, 13(7), 638 .

Occupational Safety and Health Administration "https://www.osha.gov/SLTC/scaffolding/constructio n.html"

Pui Tecka, A, G., Abdullah, M, N., Asmonib, M., Misnanb, M, S., Jaafarb, M, N., Yim Meib, J, L., 2014 "A Review on the Effectiveness of Safety Training Methods for Malaysia Construction Industry" Jurnal Teknologi (Sciences \& Engineering) 74:2 (2015), 9-.

Rubio-Romero, J., Rubio Gámez, M, C., CarrilloCastrillo, J, A., 2013. "Analysis of the safety conditions of scaffolding on construction sites" Safety Science 55 (2013) 160-164.

Sacks, R., Perlman, A., and Barak, R. (2013). Construction safety training using immersive virtual reality. Construction Management and Economics.

Saurin, Guimarães, 2006. "Ergonomic assessment of suspended scaffolds" International Journal of Industrial Ergonomics 36 (3), 229-237.

Sawacha, E., Naoum, S., \& Fong, D. (1999). Factors affecting safety performance on construction sites. International journal of project management, 17(5), 309-315.

Thabet, W., Shiratuddin, M.F. \& Bowman, D. (2002), Virtual Reality in Construction, Engineering Computational Technology, Saxe-Coburg Publications, pg. 25 - 52 (Chapter Contributor), SaxeCoburg Publications, 2002: ISBN 1-874672-17-2.

Zhao, D., and Lucas, J., 2013." Virtual reality simulation for construction safety promotion" International Journal of Injury Control and Safety Promotion, 2015 Vol. 22, No. 1, 57-67. 